\title{
The effect of tranexamic acid on blood loss after vaginal delivery
}

\author{
Jayaraman Nambiar $\mathbf{M}^{1, *}$, Keerthi Somu ${ }^{2}$ \\ ${ }^{1}$ Professor, ${ }^{2} J u n i o r$ Resident, Dept. of Obstetrics and Gynaecology, Kasturba Medical College, Manipal, \\ *Corresponding Author: Jayaraman Nambiar M \\ Email: drramnambiar@gmail.com
}

Received: $12^{\text {th }}$ October, 2018

Accepted: $16^{\text {th }}$ November, 2018

\begin{abstract}
Objectives: To find out the effect of tranexamic acid on blood loss after vaginal delivery.

Materials and Methods: In this observational study, 100 women with a singleton pregnancy were allocated to receive one gram intravenous tranexamic acid or no drug in addition to 10 units of oxytocin after delivery of the fetus. Blood loss calculated by a graduated blood bag. Pre and post-delivery hemoglobin and hematocrit are determined.

Results: The mean blood loss $(245 \mathrm{ml}$ vs $327 \mathrm{ml}, \mathrm{p}=<0.01)$ was significantly lower in the study group compared to the control group. The post-delivery hemoglobin and hematocrit $(11.4 \mathrm{gm} / \mathrm{dl}, 35 \% \mathrm{vs} 10.5 \mathrm{gm} / \mathrm{dl}, 32 \%, \mathrm{p}<0.01)$ was significantly lower in study group compared to control group.

Conclusions: Tranexamic acid helps to reduce the amount of blood loss in vaginal delivery.
\end{abstract}

Keywords: Postpartum hemorrhage, Tranexamic acid, Vaginal delivery.

\section{Introduction}

Labor is a physiological process, but it is often associated with morbidity and mortality. Bleeding is a common cause of maternal death. Postpartum hemorrhage is defined as blood loss of $500 \mathrm{~mL}$ or more after delivery within 24 hours. ${ }^{1}$ The foremost cause of maternal mortality is postpartum hemorrhage. Incidence of PPH is reported as 2\%- $4 \%$ after vaginal delivery and $6 \%$ after cesarean section. According to India Sample registration scheme (SRS) 2001-2003, PPH accounts $38 \%$ of maternal deaths. ${ }^{2}$ By timely and appropriate management, the deaths from PPH can be avoided. The most common being use of prophylactic uterotonics in third stage of labor. The pathophysiology of PPH involves mechanical and clotting mechanism. By using prohemostatic drugs like tranexamic acid a biochemical hemostatic effect can be expected. Tranexamic acid decreases the lysis of fibrin clots. ${ }^{3,4}$ Since 1960s, tranexamic acid, an anti-fibrinolytic agent has been used in different medical and surgical conditions. In a systematic review by Cochrane review it is recommended that more studies are needed to assess the efficacy of tranexamic acid to reduce blood loss. ${ }^{5}$ Efficacy of tranexamic acid has been evaluated in obstetrics and gynecology in reducing blood loss in conditions like menorrhagia, myomectomy, ${ }^{6}$ postpartum blood loss in elective cesareansections, ${ }^{7}$ ovarian tumors. ${ }^{8}$ Many studies have suggested that tranexamic acid is reducing blood loss after delivery. ${ }^{9-11}$ Tranexamic acid is a very easily available drug and is cheap. Though there are concerns about thrombosis with the use of this drug there are many studies which suggested that the drug can be safely used without the risk of thrombosis. ${ }^{12,13}$ Decreasing the blood loss after delivery would help a long way in reducing maternal mortality. The purpose of this study was to find out the efficacy of tranexamic acid in reducing blood loss after delivery.

\section{Materials and Methods}

This study is prospective observational study, carried out over a period from August 2015 to August 2017, in the department of Obstetrics and Gynecology, in a tertiary care hospital. Prior to enrolment ethical committee clearance was obtained from Hospital Ethical Committee (IEC: 551/2015). Prior to enrolment, written informed consent was attained from all women participated in the study. All women were explained purpose of study and consent was taken in the language that they understand.

The eligible participants were all women aged 18-35 years with a term singleton pregnancy with cephalic presentation who had vaginal delivery. Patients with grand multiparity (parity $>5$ ), uterine surgery and uterine myoma were excluded from the study. Patients with known coagulation disorders. Anaemia, were also excluded from the study. Patients who underwent cesarean section were excluded from the study.

Hundred pregnant women entered the study. There were 50 subjects in control group and 50 in the study group. Patients in labor either spontaneous or induced were enrolled for the study. Patients with aforementioned exclusion criteria are not included. A structured proforma was designed to record the demographic details, past history and delivery details of all the subjects enrolled for the study. The pre-delivery heamoglobin levels and PCV were noted in each patient. Monitoring of labor done. Ten units Inj. Oxytocin 10 units was given to the mother IM within 1 min of delivery of the baby, followed by Inj. Tranexamic acid 1 gram slow IV in study group. In control group no additional drug was given apart from Inj. Oxytocin. A calibrated blood collecting bag was used to measure the blood loss. The calibrated bag was placed under the patients buttock to measure the blood loss. Patients were continuously monitored for clinical signs of thrombosis 
or other complications. Complications if any, noted. Post-delivery Hemoglobin levels and PCV were noted 24 hours after delivery. Blood loss and change in Hemoglobin levels and PCV were noted in each group.

\section{Results}

All 100 pregnant women allocated into the groups were analyzed (Fig. 1). The two groups matched in terms of socio-demographic, and also in terms of reproductive, delivery characteristics, newborn weight. The demographic characteristics of the recruited women are shown in Table 1 . The amount of blood loss in study and control group was $245 \mathrm{ml}$ and $327 \mathrm{ml}$ respectively which is significant $(\mathrm{P}<0.01)$. There was a significant difference in the post-delivery Hemoglobin $(\mathrm{P}<0.01)$ and PCV ( $\mathrm{P}<0.01)$ between the groups. The difference of Hemoglobin and PCV decline in the study group and in control group was statistically significant $(\mathrm{P}<0.01)$. The results are showed in Table 2 . No adverse effects were observed with the use of tranexamic acid in the study.

Table 1 Demographic and obstetric characteristics of participants by group

\begin{tabular}{|l|c|c|c|}
\hline \multicolumn{1}{|c|}{$\mathbf{N = 1 0 0}$} & $\begin{array}{c}\text { Study group } \\
\mathbf{N = 5 0}\end{array}$ & $\begin{array}{c}\text { Control group } \\
\mathbf{N = 5 0}\end{array}$ & P Value \\
\hline Age in years & $27.76 \pm 3.56$ & $26.82 \pm 2.63$ & 0.13 \\
\hline BMI & $26.57 \pm 2.2$ & $25.8 \pm 1.62$ & 0.43 \\
\hline Primipara & 28 & 39 & 0.39 \\
\hline Multipara & 22 & 11 & 0.79 \\
\hline Sponatenous labour & 39 & 41 & 0.32 \\
\hline Induced labour & 11 & 9 & 0.30 \\
\hline Stage 1 duration in minutes & $360 \pm 30.6$ & $309 \pm 20.13$ & 0.24 \\
\hline Satge 2 duration in minutes & $24.47 \pm 10.3$ & $23.26 \pm 9.1$ & 0.63 \\
\hline Stage 3 duration in minutes & $8.5 \pm 3.9$ & $8.6 \pm 4.1$ & 0.73 \\
\hline Birth weight in gms & $2912.2 \pm 325.06$ & $3000.4 \pm 388.3$ & 0.73 \\
\hline
\end{tabular}

Table 2: Comparison of hemoglobin and hematocrit and blood loss between the groups

\begin{tabular}{|l|c|c|c|}
\hline \multicolumn{1}{|c|}{$\mathbf{N = 1 0 0}$} & Study group N=50 & Control group N=50 & P Value \\
\hline Pre-delivery Hb $(\mathrm{gms} / \mathrm{dl})$ & $12.1 \pm 0.12$ & $12.3 \pm 0.11$ & 0.27 \\
\hline Post-delivery Hb $(\mathrm{gms} / \mathrm{dl})$ & $11.4 \pm 0.89$ & $10.5 \pm 0.73$ & $<0.01$ \\
\hline Pre-delivery PCV & $37.07 \pm 0.36$ & $37.64 \pm 0.38$ & 0.28 \\
\hline Post-delivery PCV & $35.09 \pm 2.54$ & $32.24 \pm 2.54$ & $<0.01$ \\
\hline Difference in Hb $(\mathrm{gms} / \mathrm{dl})$ & $0.7 \pm 0.48$ & $1.7 \pm 0.70$ & $<0.01$ \\
\hline Difference in PCV & $1.6 \pm 1.29$ & $5.4 \pm 2.33$ & $<0.01$ \\
\hline Blood loss(ml) & $245 \pm 42.19$ & $327 \pm 44.96$ & $<0.01$ \\
\hline
\end{tabular}

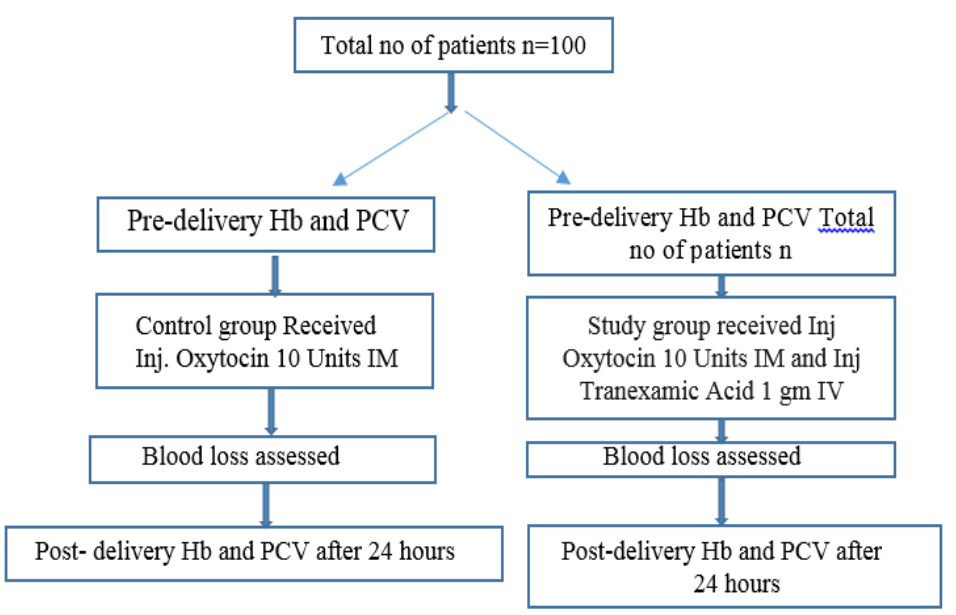

Fig. 1: Total of 100 patients who underwent normal delivery

Out of which 50 patients in study group, received Inj. Tranexamic acid along with Inj Oxytocin 10 units IM and 50 patients in control group received only Inj. Oxytocin 10 units IM.

\section{Discussion}

Tranexamic acid given prophylactically before the surgery has shown to reduce the blood loss, by inhibition of fibrinolysis. ${ }^{8,12}$ In Obstetrics and Gynecology 
tranexamic acid has been used extensively to reduce the blood loss either orally in menorrhagia or during myomectomy or cesarean section.-8 The amount of blood loss and the need of post-operative blood transfusions have come down with the perioperative use of tranexamic acid. There are no serious side effects associated with the use of tranexamic acid. ${ }^{13}$ The present study is a observational case control study, conducted from August 2015 to August 2017, in a tertiary care hospital to assess the efficacy of tranexamic acid An analysis was made for 100 women who underwent normal vaginal delivery where they are divided into 2 groups, one who received tranexamic acid as well as Oxytocin and the other group who received only Inj Oxytocin. In this study, the mean estimated blood loss is $245 \mathrm{~mL}$ in study group and 327 in control group. There was significant reduction in blood loss with the addition of tranexamic acid. Similarly there was significant difference between $\mathrm{Hb}$ and PCV post-delivery between the two groups.

Gungorkuk et al. did a randomized trial in 439 patients undergoing normal delivery and there was a significant decrease in blood loss in tranexamic group compared to placebo group. ${ }^{11}$ In 2015 , Priyankur Roy et al conducted a study to find out the efficacy of tranexamic acid in the reduction of blood loss after delivery. ${ }^{14}$ The study found good reduction in blood loss with the use of tranexamic acid. A study by Vijayalaxmi Raghavendra Gobbur et al found that tranexamic acid reduces blood loss during cesarean section. ${ }^{15}$ Though there are concerns about thrombosis in a study about thrombosis with the use tranexamic acid, ${ }^{16}$ we did not observe any side effects associated with tranexamic acid.

Many studies have also proven less blood loss during cesarean section with the use of tranexamic acid. ${ }^{17,18}$ Use of tranexamic thus would also reduce blood loss in patients undergoing cesarean section.

There was significant decrease in blood loss when tranexmaic acid was used in our study. Use of tranexamic acid in third stage labor would thus help in reducing blood loss. Postpartum bleeding is the commonest cause of maternal moratlity. Tranexamic acid is a readily available and inexpensive drug. ${ }^{19}$ Hence its use should be encouraged to reduce blood loss. There was no side effects with the use of tranexamic acid in our study. Larger studies involving larger number of women are needed to evaluate the efficacy of tranexamic acid. Current study involved only a group of 100 women.

\section{Conclusion}

From our study its clear that use of tranexamic acid would help to reduce blood loss during delivery. It's a cheap and readily available drug. Its use along with oxytocics would help in reduce blood loss during delivery. Hemorrhage being the commonest cause of maternal mortality its use would help a long way in preventing maternal mortality due to bleeding.

\section{References}

1. Mavrides E, Allard S, Chandraharan E, Collins P, Green L, Hunt BJ, Riris S. Thomson AJ on behalf of the Royal College of Obstetrici ans and Gyna ecologists. Prevention and management of postpartum haemorrhage. BJOG. 2016;124:e106-e149.

2. RGI (2006) Maternal mortality in India: 1997-2003: Trends, causes and risk factors, Office of the Registrar General \& Census Commissioner, India, New Delhi.

3. Roberts I, Ker K. Tranexamic acid for postpartum bleeding. Int J Gynaecol Obstet. 2011;115(3):220-221.

4. Shakur H, Elbourne D, Gulmezoglu M et al. The WOMAN Trial (World maternal antifibrinolytic trial): tranexamic acid for the treatment of postpartum haemorrhage: an international randomised, double blind placebo controlled trial. Trials 2010;11:40.

5. Roberts I, Ker K. Tranexamic acid for postpartum bleeding. Int J Gynaecol Obstet. 2011;115(3):220-221.

6. Novikova N, Hofmeyr GJ, Cluver C. Tranexamic acid for preventing postpartum haemorrhage. Cochrane Database of Systematic Reviews 2015, Issue 6. Art. No.: CD007872. DOI: 10.1002/14651858.CD007872.

7. Ngichabe S, Obura T, Stones W. Intravenous tranexamic acid as an adjunct haemostat to ornipressin during open myomectomy. A randomized double blind placebo controlled trial. Annals of Surgical Innovation and Research. 2015;31;9(1):10.

8. Bhatia SK, Deshpande H. Role of tranexamic acid in reducing blood loss during and after caesarean section. Medical Journal of Dr. DY Patil University. 2015;8(1):21.

9. Lundin ES, Johansson T, Zachrisson H, Leandersson U, Bäckman F, Falknäs L, Kjølhede P. Single- dose tranexamic acid in advanced ovarian cancer surgery reduces blood loss and transfusions: double- blind placebo controlled randomized multicenter study. Acta obstetricia et gynecologica Scandinavica. 2014;93(4):335-44.

10. Mirghafourvand M, Mohammad- Alizadeh S, Abbasalizadeh F, Shirdel M. The effect of prophylactic intravenous tranexamic acid on blood loss after vaginal delivery in women at low risk of postpartum haemorrhage: a doubleblind; randomised controlled trial. Australian and New Zealand Journal of Obstetrics and Gynaecology. 2015;55(1):53-8.

11. Roy P, Sujatha MS, Bhandiwad A, Biswas B. Role of Tranexamic Acid in Reducing Blood Loss in Vaginal Delivery. The Journal of Obstetrics and Gynecology of India. 2016;66(1):246-50.

12. Gungorduk K, Asıcıoğlu O, Yıldırım G, Ark C, Tekirdağ Aİ, Besımoglu B. Can intravenous injection of tranexamic acid be used in routine practice with active management of the third stage of labor in vaginal delivery? A randomized controlled study. American Journal of Perinatology. 2013;30(05):407-14.

13. Huang F, Wu D, Ma G, Yin Z, Wang Q. The use of tranexamic acid to reduce blood loss and transfusion in major orthopedic surgery: a meta-analysis. Journal of Surgical Research. 2014;186(1):318-327.

14. Clinical observation of blood loss reduced by tranexamic acid during and after cesarian section: a multi-center, randomized trial (Eur J Obstet Gynecol Reprod Biol. 2004;112:154-57).

15. Priyankur Roy, M. S. Sujatha, Ambarisha Bhandiwad, Bivas Biswas. Obstet Gynaecol India. 2016;66(Suppl 1):246-250. 
16. Gobbur VR, Shiragur SS, Jhanwar UR, Tehalia MJ. Efficacy of tranexamic acid in reducing blood loss during lower segment caesarean section. Int J Reprod Contracept Obstet Gynecol. 2014;3:414-7.

17. Tanaka N, Sakahashi H, Sato E. Timing of the administration of tranexamic acid for maximum reduction in blood loss in arthroplasty of the knee. J Bone Joint Surg Br. 2001;83(5):702-705.

18. Gohel M, Patel P, Gupta A. Efficacy of tranexamic acidin decreasing blood loss during and after cesarean section: a randomized case controlled prospective study. J Obstetr Gynaecol India. 2007; 57: 228-230.

19. Abdel-Aleem H, Alhusaini TK, Abdel-Aleem MA.

Effectiveness of tranexamic acid on blood loss in patients undergoing elective cesarean section: randomized clinical trial. J Matern Fetal Neonatal Med. 2013;26(17):17051709.

20. Saberi H, Miri SM, Poordel M. The effects of topically applied tranexamic acid on reduction of post laminectomy haemorrhage. Tehran Univ Med J (TUMJ). 2010;68(9):527-533.

How to cite this article: Jayaraman N.M, Somu $\mathrm{K}$. The effect of tranexamic acid on blood loss after vaginal delivery. Indian J Obstet Gynecol Res. 2018;5(4):559-562. 